\title{
Effect of information about organic production on beef liking and consumer willingness to pay
}

\author{
F. Napolitano ${ }^{\mathrm{a}, *}$, A. Braghieri ${ }^{\mathrm{a}}$, E. Piasentier ${ }^{\mathrm{b}}$, S. Favotto $^{\mathrm{b}}$, S. Naspetti ${ }^{\mathrm{c}}$, R. Zanoli $^{\mathrm{c}}$ \\ a Dipartimento di Scienze delle Produzioni Animali, Università degli Studi della Basilicata, Viale dell'Ateneo Lucano 10 - 85100 Potenza, Italy \\ b Dipartimento di Scienze Animali, Università degli Studi di Udine, Via S. Mauro 2 - 33010 Udine, Italy \\ c DIIGA, Università Politecnica delle Marche, Via Brecce Bianche - 60131 Ancona, Italy
}

\section{A R T I C L E I N F O}

\section{Article history:}

Received 30 October 2008

Received in revised form 8 July 2009

Accepted 10 August 2009

Available online 12 August 2009

\section{Keywords:}

Organic production

Beef liking

Expectancy

Willingness to pay

\begin{abstract}
A B S T R A C T
The present study was aimed to assess the effect of information about organic production on beef liking and consumer willingness to pay. Mean scores of perceived liking were higher for organic beef $(\mathrm{OB})$ as compared to conventional beef (CB). Expected liking scores were higher for OB than for $\mathrm{CB}$. For OB the expected liking was significantly higher than the perceived liking expressed in blind conditions (negative disconfirmation), whereas for $\mathrm{CB}$ no difference was observed. Consumers completely assimilated their liking for $\mathrm{OB}$ in the direction of expectations. Consumers showed a willingness to pay for OB higher than the suggested price $(P<0.001)$, the latter corresponding to the local commercial value for organic beef. We conclude that the information about organic farming can be a major determinant of beef liking, thus providing a potential tool for meat differentiation to traditional farms.
\end{abstract}

(c) 2009 Elsevier Ltd. All rights reserved.

\section{Introduction}

A number of western countries are showing oversupplies in the organic meat sector (Organic Monitor Ltd., 2006). The general sense among consumers who would not buy organic products is that they are usually more costly: high prices are perceived as the biggest problem for one third of respondents in Asia Pacific and over $40 \%$ of European and North American people (ACNielsen, 2005).

Meeting organic certification requirements usually implies higher production costs. For example, it is reported that the cost of producing organic beef in the United Kingdom is $20 \%$ higher than under conventional methods. However, for consumers from western countries, price is not the only determinant behind animal-food purchases as they are acquiring an increasing interest in farming practices and standards. Consumers do not seek the cheapest food but the best value for money, i.e. the maximum benefit for what they are prepared to spend (McInerney, 2004).

Many aspects can be used by consumers to perform their food choices. Intrinsic (e.g. cut, colour, fat rim) and extrinsic cues (price, origin, production and nutritional information) are used to form expectations about product quality attributes, the latter can be classified in two categories: those experienced before or during consumption (experience quality attributes: e.g. price and sensory properties) and those not experienced directly, such as healthiness,

\footnotetext{
* Corresponding author. Tel.: +39 0971 205078; fax: +39 0971205099.

E-mail address: fabio.napolitano@unibas.it (F. Napolitano).
}

naturalness, ethical aspects, etc., which should be communicated to be perceived as they are credence characteristics that cannot be confirmed either before or after purchase (Grunert, Bredhal, \& Brunsø, 2004). Ethical concerns are becoming increasingly important in the hierarchy of reasons to purchase organic products. Although tangible aspects can markedly affect most purchasing decisions, independently from the knowledge and awareness of the consumer, intangible attributes are important for high-involvement consumers possessing enough beliefs and attitudes (McEachern and Schröder, 2002). For these consumers, such intangible attributes play a central role in defining product quality. Organic foods produced according to strictly defined standards are able to satisfy the expectations of contemporary consumers concerned with various aspects of food quality. Therefore, the provision of information about the benefits of organic farming on environment, animal welfare and health can increase consumer awareness and willingness to buy organic products.

According to a recent on line survey (ACNielsen, 2005), organic alternatives are purchased mainly for health reasons. Therefore, there is a potential to increase consumer awareness of the environmental and animal benefits of organic foods by means of information (Zanoli et al., 2004). In addition, it has been observed that consumers are willing to access to more information about organic food (Brennan, Gallagher, \& McEachern, 2003).

Numerous studies have been conducted on the effect of information on food liking (Aaron, Mela, \& Evans, 1994; Daillant \& Issanchou, 1993). In particular, information about the manufacturing process (organic vs. OGM) can affect product acceptability 
(Caporale \& Monteleone, 2004). Recent studies have been conducted on the effect of information about animal welfare on lamb (Napolitano et al., 2007a) and beef liking (Napolitano, Caporale, Carlucci, \& Monteleone, 2007b). All these experiments have shown that expectations induced by the information can affect the quality perception. Thus, if expectations are either positively (the liking score of the product tasted without external information is higher than expected) or negatively disconfirmed (the product is worse than expected), the assimilation model is generally applicable, which means that hedonic ratings move towards the expectations when an external information is given compared to tasting without external information (Anderson, 1973; Cardello \& Sawyer, 1992).

The price that people are willing to pay is the major determinant of the market share of organic meat. Although intent to purchase depends upon the interactions of quality attributes such as appearance and colour (Brewer \& McKeith, 1999), it has been found a more consistent effect of organic labelling as compared to some sensory characteristics on the price offered by consumers for organic pork (Dransfield et al., 2005). Using questionnaires on organic foods in Spain, consumers appeared to be prepared to pay about $12 \%$ more for organic red meats and chicken (Gil, Gracia, \& Sanchez, 2000). In France and The Netherlands, questionnaire responses suggested that almost half of consumers would pay $20 \%$ more for pork from pigs raised outdoors (Carpentier \& Latouche, 2005). Dransfield et al. (2005) stated that those studies over-estimated the premiums consumers would be willing to pay, while their results suggest that people would offer $5 \%$ extra, with about one-fifth of consumers willing to pay $20 \%$ extra, for organic pork. However, hedonic and purchase intent measurements may be not representative of the real behaviour of consumers. They may declare high preferences and purchase intent for products with high-perceived quality, albeit not buying them under economic constraints (Lange, Rousseau, \& Issanchou, 1999).

Recently, Lange, Martin, Chabanet, Combris, and Issanchou (2002) and Napolitano, Pacelli, Girolami, and Braghieri (2008) observed that, as for food liking, the assimilation model is also applicable to consumer willingness to pay. As a consequence, it can be hypothesized that information about the organic manufacturing process can increase both meat acceptability and willingness to pay thus providing a means to cover the extra production costs sustained by organic farmers.

Little is known on the effect of the information about organic production on the real consumer willingness to pay for meat. Recent studies demonstrated that auctions are able to place consumers in real situations where they can show their true preferences. In particular, the Vickrey second price auction is widely used to assess consumer willingness to pay real goods (e.g. Melton, Huffman, Shogren, \& Fox, 1996), including foods (Lange et al., 2002), and the value consumers give to food safety (e.g. Hayes, Shogren, Shin, \& Kliebenstein, 1995) and animal welfare (Napolitano et al., 2008). According to this specific type of auction consumers are individually asked to submit a sealed bid corresponding to the highest price they would agree to pay for a particular product. The highest bidder (i.e. the winner), by paying the second highest price, has the opportunity to buy a product at a price equal to or, more often, lower than the value he assigns to the product (Vickrey, 1961). People have an incentive to truthfully reveal their private preferences because the auction separates what they say from what they pay. Underbidding consumers risk foregoing a profitable purchase, whereas overbidding consumers risk making an unprofitable purchase.

The present study was aimed to assess the effect of information about the organic production process on beef liking and verify whether consumers confirm their willingness to pay the extra costs associated with organic farming in a situation where a potential purchase performed by consumers is included.

\section{Materials and methods}

\subsection{Products}

Beef was obtained from 12 Podolian young bulls aged 16 months and reared either in conventional (CB) or organic local farms (OB). Two animals from three organic and three conventional farms were used. Carcasses were aged 15 days in order to increase meat tenderness and make the product acceptable from a sensory point of view (Braghieri et al., 2005). Both products were obtained from the central part of the muscle Longissimus dorsi lumborum (loin) as suggested by Wheeler, Shackelford, and Koohmaraie (2007) to obtain slices with similar sensory properties. Meat samples $(10 \times 10 \times 1 \mathrm{~cm})$ were grilled at $300^{\circ} \mathrm{C}$ to an internal temperature of $75^{\circ} \mathrm{C}$ assessed using a thermocouple probe inserted into the meat. This temperature was chosen as Podolian beef is usually served well done (Napolitano et al., 2007b). Mean cooking time was $6 \mathrm{~min}$. Samples were offered to the subjects immediately after cooking in booths where salt was available ad libitum.

\subsection{Subjects}

Subjects were recruited in three different locations: Potenza (main city in the region Basilicata, southern Italy), Ancona (main city in the region Marche, central Italy) and Udine (main city in the region Friuli Venezia Giulia, northern Italy). The consumer panel consisted of 50 subjects for southern and northern Italy locations and 45 subjects for central Italy location. They were recruited on the basis of age and level of education. In addition, subjects were selected using predetermined screening criteria based on consumption frequency of beef and organic products.

One hundred and ninety subjects were interviewed and were asked their frequency of consumption of beef at home $(1=$ never; $2=$ once a year or less; $3=3-5$ times a year; $4=$ less than once a month; 5=1-2 times a month; $6=$ more than twice a month; 7 = at least once a week).

The selected consumer panel included subjects who reported to consume beef at least " $1-2$ times a month" and organic products occasionally. In particular, in relation to organic products consumers were distributed as follows: "once a year or less" $=77$, "3-5 times a year" $=35$, "less than once a month" $=23$, " $1-2$ times a month" $=10$. Subjects had a mean age of 49 years and were almost equally distributed for sex. The main features of the subjects participating to the consumer panel are depicted in Table 1.

\subsection{Experimental design}

The experiment was planned in four tests (Table 2). In the first test the consumers were offered both $\mathrm{CB}$ and $\mathrm{OB}$ in a balanced order of presentation. They were asked to taste the meat and rate their liking receiving no information on the products (perceived

Table 1

Socio-demographic features of the subjects participating to the consumer test.

\begin{tabular}{llll}
\hline & Levels & Number & Percentage \\
\hline \multirow{2}{*}{ Age } & 20-39 years & 41 & 28 \\
& 40-59 years & 49 & 34 \\
Sex & $>59$ years & 55 & 38 \\
& Female & 64 & 44 \\
Education level & Male & 81 & 56 \\
& Primary school & 7 & 5 \\
& Secondary school & 17 & 12 \\
& High school & 59 & 40 \\
& Graduated & 51 & 35 \\
& Post-graduate & 11 & 8 \\
\hline
\end{tabular}


Table 2

Summary of the experimental design for the assessment of consumer liking (L) and willingness to pay (WTP).

\begin{tabular}{|c|c|c|c|c|}
\hline Test & Day & Stimulus presentation & Type of evaluation & Type of rating \\
\hline 1 & 1 & Beef & Tasting without information & Blind $\mathrm{L}$ \\
\hline 2 & 1 & Information & Expectation & Expected L \\
\hline 3 & 2 & Beef + information & Tasting with information & Actual L \\
\hline 4 & 2 & Product display & Auction & WTP \\
\hline
\end{tabular}

liking). In the second test the subjects received two sheets with the information concerning the farming systems (conventional or organic). They were asked to read carefully the information and give their liking expectation for that product (expected liking). First and second tests were performed in the same day. The day after the third test was performed: the consumers were given OB only along with the information sheet. They were instructed to read the information before tasting the sample and express their liking score (actual liking).

\subsection{Hedonic data acquisition}

Consumers rated their liking on a 9-point hedonic scale labelled at the left end with "extremely unpleasant", at the right end with "extremely pleasant" and at the central point with "neither pleasant nor unpleasant” (Kähkönen, Tuorila, \& Rita, 1996).

In tests 2 (expectations produced by information) and 3 (acceptability generated by information and tasting of the product) the following information concerning the farming systems were given to consumers:

(1) Conventional beef: conventional beef cattle farming ensure standards of animal welfare as set by the current legislation; the administration of pharmaceuticals is allowed within the suspension limits, as well as the use of GMO and chemicals for the production of animal feeds, in accordance with the current legislation; a high stocking density per hectare is allowed.

(2) Organic beef: organic beef cattle farming practices ensure standards of animal welfare higher than those set by the current legislation by promoting grazing systems and the expression of species-specific natural behaviour; the use of pharmaceuticals is markedly reduced; the use of GMO and chemicals for the production of animal feeds is banned; stocking density per hectare is low in order to reduce the impact of faming on the environment.

In order to validate such information, a test was conducted on 31 subjects who were not involved in the experiment. They were asked to read each piece of information concerning organic beef (animal welfare, product safety and environmental pollution) either separately on three different information sheets or together on one sheet (only in this latter case consumers were told that the product was actually organic) and score their liking expectations. The four information sheets were randomly offered to consumers.

\subsection{Vickrey auction}

The second price Vickrey auction (Vickrey, 1961) was used to assess consumer willingness to pay organic beef. Participants attended a short presentation explaining the procedure to be followed for the auction. It was made clear that the submission of bids implied a commitment to buy the product. Participants agreeing to the procedure signed a consent and received $10 €$ in cash. Subsequently, a formal training on the use of the Vickrey second price auction was conducted. It was explained that the maximum price accepted to pay for $100 \mathrm{~g}$ of organic beef had to be written on paper, separately by each participant. The bid had to be comprised between 0.00 and $5.50 €$. On each form provided to consumers there was a suggested price (ranging from 0.29 to $5.42 €$ ). It was explained that they could offer lower or higher prices. The suggested prices used in this study can be regarded as anchor points, which in the presence of other information, such as the information on organic production, have weak or no effects on consumer bids (Chapman \& Johnson, 1994). Therefore, these prices were used to construct a mean value $(2.07 €)$ corresponding to the actual commercial price of organic beef in Italy to which compare the consumer bids. The participant submitting the highest price (winner) had to buy the product, not at the submitted price, but at the second highest price (i.e. the second highest submitted bid). In case of more consumers offering the same highest bid only one participant, randomly chosen by another consumer, would be selected as winner. This procedure allowed one of the participants to buy organic beef at a price lower than or equal to the price they would normally accept to pay. It was also explained that the study aimed to know the value that the product had for the consumers, not its commercial value, and that the best option for them was the submission of their real reservation price. In order to ascertain that all participants correctly interpreted the procedure, some practice was conducted using snacks. Subsequently, an auction was conducted where consumers submitted bids after the display of a $100 \mathrm{~g}$ slice of organic beef.

\subsection{Statistical analysis}

Data were subjected to analysis of variance with geographical location, age, sex and level of education as factors. The Student's paired $t$-tests were used to evaluate differences between mean scores either obtained for the two products ( $\mathrm{OB}$ and $\mathrm{CB}$ ), or obtained for the same product under different conditions (tasting only, information only, tasting with information). The same test was used to compare the suggested price for organic beef and the actual bids offered by consumers. The relationship between OB hedonic data and willingness to pay OB was computed using the Pearson's coefficient of correlation.

Data gathered for the validation of information were subjected to analysis of variance with one factor (type of information).

\section{Results and discussion}

\subsection{Validation of information}

Data from the test of validation showed that the type information significantly affected the expected liking $(P<0.01)$. Expectations generated by the complete information on the organic production system were higher than those elicited by the information on animal welfare $(P<0.05)$ and environmental pollution $(P<0.01)$, whereas only tended to be higher than the expectations produced by the information on food safety $(P<0.15)$. Conversely, no differences were observed between the expectations generated by the three different pieces of information. Therefore, consumers specifically responded to the fact that the beef was organic rather than to positive messages in general. 


\subsection{Comparison between products}

Ratings given by consumers to $\mathrm{OB}$ and $\mathrm{CB}$ are summarised in Table 3. Consumers rated both products at scores above the central point ( $5=$ neither pleasant nor unpleasant) for perceived liking. These results indicate that the meat from both organically and conventionally reared beef cattle was characterised by a good eating quality. However, mean scores of perceived liking were higher for OB as compared to CB $(P<0.001)$. No information is available on the effect of organic farming on beef acceptability, although previous studies reported a minor increase of flavour (Marino et al., 2006) and decrease of tenderness (Braghieri et al., 2005). In this study organic farming practices may have induced a higher acceptability as compared with conventional techniques with scores above 7 (pleasant). Such differences may be attributed to the fact that beef obtained from animals raised on pasture (organic beef), unlike conventional beef, may acquire a number of different compounds affecting meat flavour (Braghieri \& Napolitano, 2009). However, the small number of animals per production system may have also affected the results. Therefore, larger groups of animals should be used to confirm these results.

Both expected liking scores were above the central point. A high expected liking for conventional beef is likely to be due to a satisfactory consumer trust in legislative processes and transparency. Expected liking scores were higher for $\mathrm{OB}$ than for $\mathrm{CB}(P<0.001)$. These results indicate that consumers are aware of the possible positive effects of organic farming on product quality and safety; the latter aspect being related to the banning of fertilisers and pesticides in crop production, and chemicals, GMO food and animal flour in animal feeding. Earlier research suggests that the positive consumer responses in our study may be related to consumer expectations that organic food is safer, healthier and high quality (Brennan et al., 2003; Michaelidou \& Hassan, 2008). Fresh meat is usually commercialised as undifferentiated product. For instance, Grunert (1997) suggests that the butcher is considered as an expert by consumers and, therefore, reliable to predict meat quality and characteristics. As long as fresh meat is mainly sold as a commodity, there is also only a limited incentive for meat producers to differentiate their product (Grunert et al., 2004). Any form for improved or otherwise differentiated meat quality requires new ways to signal the quality to the consumer. Thus, meat product differentiation needs a constant and reliable signalling of quality through appropriate information given to consumers in order to motivate them and increase their willingness to buy and pay for meat (Bredahl, 2004). This differentiation can be based on both product or process characteristics. For animal-based products, pro-

Table 3

Rating ( \pm S.E.) given by the consumer panel during the three hedonic tests.

\begin{tabular}{lll}
\hline Type of rating & Organic beef & Conventional beef \\
\hline Perceived liking & $7.12 \pm 0.11 \mathrm{a}$ & $6.25 \pm 0.12 \mathrm{~b}$ \\
Expected liking & $7.68 \pm 0.09 \mathrm{a}$ & $6.21 \pm 0.15 \mathrm{~b}$ \\
Actual liking & $7.58 \pm 0.09$ & NR \\
P-E & $-0.56^{* * *}$ & 0.04 \\
& Negative disconfirmation $^{\mathrm{a}}$ & No disconfirmation \\
A-P & $0.45^{* * *}$ & - \\
& Assimilation $^{\mathrm{b}}$ & \\
A-E & -0.12 & - \\
& Complete $^{\mathrm{c}}$ & \\
\hline
\end{tabular}

$\mathrm{P}=$ perceived liking mean scores (baseline); $\mathrm{E}=$ expected liking mean scores;

$\mathrm{A}=$ actual liking mean scores (with information); $\mathrm{NR}=$ not recorded.

$\mathrm{a}, \mathrm{b}=P<0.001$.

*** $P<0.001$

a The product is worse than expected.

b Actual liking moves towards the expectations.

c Assimilation occurs, and actual liking is not different from expectations. cess characteristics may be represented by the farming practices and the related organic standards. In fact, consumers showed a WTP for OB higher than the suggested price $(P<0.001)$, the latter corresponding to the commercial value for organic beef (Table 4). As the main limit to purchasing organic meat remains price, due to high production costs, which are affected by organic rules (higher space allowance, origin of feedstuffs, etc.) and small-scale production systems, one strategy to overcome this problem may be the induction of increased willingness to pay by constant and reliable quality signalling systems capable to provide an ethical value to the product, which may become even higher if associated to traditional farming systems and typical meat productions.

\subsection{Comparison between different information conditions}

Results concerning the effect of information on expected and actual liking of beef are shown in Table 3. For OB the expected acceptability was significantly different from the perceived liking expressed in blind conditions $(P<0.001)$, thus indicating that a disconfirmation occurred. In particular, the consumers found $\mathrm{OB}$ worse than expected (negative disconfirmation). These results indicate that information about farming practice can have a marked impact on consumer expectancy with organic standards associated with high expected product quality. Accordingly, previous studies revealed a marked effect of positive information about farming practices and animal welfare on actual liking of meat (Napolitano et al., 2007a,b) and willingness to pay for yogurt (Napolitano et al., 2008). No difference was observed between expected and perceived liking of $\mathrm{CB}$ expressed in blind conditions $(P>0.05)$.

A significant difference between perceived and actual liking was observed for $\mathrm{OB}$, as the former was lower than the latter $(P<0.001)$. Therefore, the information given about organic farming was able to affect the actual liking of beef. In this case, the effect of information can be explained on the basis of the assimilation model, which can be observed when the actual liking of the product moves in the direction of the expectations. In particular, the information concerning the use of organic farming techniques characterised by high levels of animal welfare, product safety and low impact on the environment had a positive impact on actual liking. Consumers completely assimilated their liking in the direction of expectations, as indicated by the fact that expectancy was not significantly different from actual liking $(P>0.05)$, which in turn showed scores close to 8 (very pleasant). This result is particularly relevant because if consumers do not completely assimilate towards expectations, repeated disconfirmations may lead to a decrease in expectations and liking, whereas in case of complete assimilation, repeated disconfirmations did not induce a decrease in expectation nor a decrease in the assimilation effect when the experiment was replicated (Lange et al., 1999).

The complete assimilation observed for this product is likely to be due to the important role played by the information in the determination of actual liking of organic beef. This information is able to address some of the currently main consumer concerns, such as product safety, animal welfare and environmental pollution. In addition, the complete assimilation was possibly facilitated by the good eating quality of the organic product, as indicated by

Table 4

Mean ratings ( \pm S.E.) of WTP.

\begin{tabular}{ll}
\hline & WTP \\
\hline Suggested price & $2.07 \pm 0.12 \mathrm{a}$ \\
Consumer bid & $3.10 \pm 0.13 \mathrm{~b}$ \\
\hline $\mathrm{a}, \mathrm{b}=P<0.001$. &
\end{tabular}


the high value of perceived liking observed in blind conditions. In fact, Moskowitz (1995) showed that it is not sufficient to state that a product has high quality standards to motivate consumers and information should be supported by real benefits and adequate sensory properties. Accordingly, it has been demonstrated that, although the increased consumer WTP for the organic labels is mainly linked to ethical concerns, the positive effect of this information is also dependent on the intrinsic characteristics and perceived quality of the product (Sirieix \& Tagbata, 2008).

\subsection{Comparison between consumers with different demographic features}

No significant effect of location was observed on both hedonic data and consumer willingness to pay. Female consumers showed higher blind $(P<0.01)$ and expected likings $(P<0.05)$ for OB than males, whereas they only tended to have higher actual likings for the same product $(P<0.10)$. As all values were increased, no effects could be detected on the disconfirmation and assimilation.

Age affected OB perceived and actual likings, and disconfirmation. Consumers from the intermediate age class (40-59 years) expressed for $\mathrm{OB}$ higher perceived $(P<0.01)$ and actual likings $(P<0.01)$ than the subjects from the low age class ( $20-39$ years), whereas no effect was observed on expected liking. Therefore, consumers from the intermediate age class showed a lower disconfirmation $(P<0.05)$.

Actual liking for $\mathrm{OB}$ was influenced by the level of instruction with lower values expressed by consumers at primary school level than at any other instruction level $(P<0.01)$. In addition, the assimilation was higher at graduated and high school levels than at secondary and primary school levels $(P<0.05)$. This result may be due to the fact that consumers with a high education level are more involved in ethical issues and sensitive to the positive information related to the organic production system.

\subsection{Relationship between organic beef liking and consumer willingness to pay}

A significant correlation was observed between consumer willingness to pay and expected liking for $\mathrm{OB}(P<0.05)$, whereas $\mathrm{OB}$ actual liking was not significantly correlated to willingness to pay $(P>0.05)$. These results suggest that willingness to pay is more dependent on information than on product sensory properties. Lange et al. (2002) observed that hedonic measures may be more appropriate for the assessment of the sensory value attributed by consumers to the product, whereas WTP may be more sensitive for the evaluation of the perceived value of a product tested in presence of external information. A significant correlation was also observed between hedonic disconfirmation and consumer willingness to pay $\mathrm{OB}(P<0.05)$ with higher levels of disconfirmation corresponding to higher bids $(P<0.05)$.

\section{Conclusion}

The main limit to purchasing organic meat remains price because of high production costs, which are affected by organic rules and small-scale production systems. One strategy to overcome this problem may be the induction of increased willingness to pay by constant and reliable quality signalling systems capable to provide an ethical value to the product.

In particular, the results showed that consumers are influenced by information about organic production and move their actual acceptability in the direction of expected liking, possibly because consumers are aware of the ethical value of organic farming and its effects on product safety. The hedonic discrepancy between ex- pected and perceived liking was totally assimilated indicating that actual liking of organic beef was markedly affected by information. The relevance of information and the good eating properties of the product may have facilitated this result. Therefore, the information about organic farming, if given to the consumers, can be a major determinant of beef liking, thus providing a potential tool for meat differentiation to traditional farms where husbandry is based on extensive rearing systems and high animal welfare standards with low use of pharmaceuticals. Accordingly, consumers are prepared to spend more for organic beef as compared to the actual commercial value of organic beef, thus indicating that reliable information about the organic farming system may markedly increase consumer willingness to pay.

\section{Acknowledgements}

The authors thank G. Impemba, N. Piazzolla, A.M. Riviezzi, F. Solfanelli for assistance with conducting the experiment. The research was funded by Regione Marche within the program E.QU.I.ZOO.BIO (Efficienza, Qualità e Innovazione nella Zootecnia Biologica).

\section{References}

Aaron, J. I., Mela, D. J., \& Evans, R. E. (1994). The influences of attitudes, beliefs and label information on perceptions of reduced-fat spread. Appetite, 22, 25-37.

ACNielsen (2005). Organic and functional foods have plenty of room to grow according to new ACNielsen global study. <http://usacnielsencom/news/>.

Anderson, R. E. (1973). Consumer dissatisfaction: The effect of disconfirmed expectancy on perceived product performance. Journal of Marketing Research, $10,38-44$

Braghieri, A., Cifuni, G. F., Girolami, A., Riviezzi, A. M., Marsico, I., \& Napolitano, F. (2005). Chemical physical and sensory properties of meat from pure and crossbred Podolian bulls at different ageing times. Meat Science, 69, 681-689.

Braghieri, A., \& Napolitano, F. (2009). Organic meat quality. In J. Kerry \& D. Ledward (Eds.), Improving the sensory and nutritional quality of fresh meat (pp. 387-417). Cambridge: Woodhead Publishing Ltd.

Bredahl, L. (2004). Cue utilisation and quality perception with regard to branded beef. Food Quality and Preference, 15, 65-75.

Brennan, C., Gallagher, K., \& McEachern, M. (2003). A review of the "consumer interest" in organic meat. International Journal of Consumer Studies, 27, 381-394.

Brewer, M. S., \& McKeith, F. K. (1999). Consumer related quality characteristics as related to purchase intent of fresh pork. Journal of Food Science, 64, 171-174.

Caporale, G., \& Monteleone, E. (2004). Influence of information about manufacturing process on beer acceptability. Food Quality and Preference, 15, 271-278.

Cardello, A. V., \& Sawyer, F. M. (1992). Effects of disconfirmed consumer expectations on food acceptability. Journal of Sensory Studies, 7, 253-277.

Carpentier, A., \& Latouche, K. (2005). French consumers' and citizens' concern: Which willingness to pay for "green pork"? In International workshop on green pork production (pp. 17-18). Paris [May 25-27].

Chapman, G. B., \& Johnson, E. J. (1994). The limits of anchoring. Journal of Behavioral Decision Making, 7, 223-242.

Daillant, B., \& Issanchou, S. (1993). Influence of sugar and fat contents on preference for cream cheese. A preliminary study. Food Quality and Preference, 4, 133-139.

Dransfield, E., Ngapo, T. M., Nielsen, N. A., Bredahl, L., Sjödén, P. O., Magnusson, M., et al. (2005). Consumer choice and suggested price for pork as influenced by its appearance, taste and information concerning country of origin and organic pig production. Meat Science, 69, 61-70.

Gil, J. M., Gracia, A., \& Sanchez, M. (2000). Market segmentation and willingness to pay for organic products in Spain. International Food and Agribusiness Management Review, 3, 207-226.

Grunert, K. G. (1997). What's in a steak? A cross-cultural study of the quality perception of beef. Food Quality and Preference, 8, 157-174.

Grunert, K. G., Bredahl, L., \& Brunsø, K. (2004). Consumer perception of meat quality and implications for product development in the meat sector - A review. Meat Science, 66, 259-272.

Hayes, D. J., Shogren, J. F., Shin, S. Y., \& Kliebenstein, J. B. (1995). Valuing food safety in experimental auction markets. American Journal of Agricultural Economics, 77, 40-53.

Kähkönen, P., Tuorila, H., \& Rita, H. (1996). How information enhances acceptability of a low-fat spread. Food Quality and Preference, 7, 87-94.

Lange, C., Martin, F., Chabanet, C., Combris, P., \& Issanchou, S. (2002). Impact of the information provided to consumers on their willingness to pay for champagne: Comparison with hedonic scores. Food Quality and Preference, 13, 597-608.

Lange, C., Rousseau, F., \& Issanchou, S. (1999). Expectation, liking and purchase behaviour under economical constraint. Food Quality and Preference, 10, 31-39. 
Marino, R., Albenzio, M., Girolami, A., Muscio, A., Sevi, A., \& Braghieri, A. (2006). Effect of forage to concentrate ratio on growth performance and on carcass and meat quality of Podolian young bulls. Meat Science, 38, 269-277.

McEachern, M. G., \& Schröder, M. J. A. (2002). The role of livestock production ethics in consumer values towards meat. Journal of Agricultural and Environmental Ethics, 15, 221-237.

McInerney, J. (2004). Animal welfare, economics and policy. Report prepared for DEFRA. <http://statistics.defra.gov.uk/esg/reports/animalwelfare.pdf> Accessed 20.09.07.

Melton, B., Huffman, W., Shogren, J., \& Fox, J. (1996). Consumer preferences for fresh food items with multiple quality attributes: Evidence from an experimental auction of pork chops. American Journal of Agricultural Economics, 78, 916-923.

Michaelidou, N., \& Hassan, L. M. (2008). The role of health consciousness, food safety concern and ethical identità on attitudes and intentions towards organic food. International Journal of Consumer Studies, 32, 163-170.

Moskowitz, H. R. (1995). The dollar value of product quality: The effect of pricing versus overall liking on consumer stated purchase intent for pizza. Journal of Sensory Studies, 10(3), 239-247.

Napolitano, F., Braghieri, A., Caroprese, M., Marino, R., Girolami, A., \& Sevi, A. (2007a). Effect of information about animal welfare, expressed in terms of rearing conditions, on lamb acceptability. Meat Science, 77, 431-436.
Napolitano, F., Caporale, G., Carlucci, A., \& Monteleone, E. (2007b). Effect of information about animal welfare and product nutritional properties on acceptability of meat from Podolian cattle. Food Quality and Preference, 18, 305-312.

Napolitano, F., Pacelli, C., Girolami, A., \& Braghieri, A (2008). Effect of information about animal welfare on consumer willingness to pay for yogurt. Journal of Dairy Science, 91, 910-917.

Organic Monitor (2006). The North American market for organic meat products. Organic Monitor Ltd.

Sirieix, L., \& Tagbata, D. (2008). Consumers willingness to pay for fair trade and organic products. In Proceedings of the 2nd scientific conference of the international society of organic agriculture research (ISOFAR) (pp. 260-263). Modena, Italy [18-20 June].

Vickrey, W. (1961). Counterspeculation, auctions, and competitive sealed tenders Journal of Finance, 16, 8-37.

Wheeler, T. L., Shackelford, S. D., \& Koohmaraie, M. (2007). Beef longissimus slice shear force measurement among steak locations and institution. Journal of Animal Science, 85, 2283-2289.

Zanoli, R., Bahr, M., Borschen, M., Laberenz, H., Naspetti, S., \& Thelen, E. (2004). The European consumer and organic food. Organic marketing initiatives and rura developmment (Vol. IV, p. 175). Aberystwyth: School of Management and Business, The University of Wales. 